\title{
Teacher Burnout at the Elementary School Level in Ghana: A Qualitative Investigation into its Causes and Effects
}

\author{
Solomon A. Boateng* \\ Ph.D. student at Keiser university Fort-Lauderdale, Florida, USA
}

*Corresponding Author: Solomon A. Boateng, Ph.D. student at Keiser university Fort-Lauderdale, Florida, USA

\begin{abstract}
Education has become a fundamental component of socio-economic development in almost every country. However, in Ghana, teachers are not given the necessary support needed to sustain and keep them in the profession. Most of the teachers finally leave the profession due to burn out and stress. Teacher burnout and stress in Ghana dates back to President Nkrumah's era, when he implement free education in the basic level all over Ghana that attracted more children and significantly increased the workload of teachers. Although, research on teacher burnout in Ghana is relatively new, teacher burnout is a problem that affects educational institutions worldwide. In fact, till date the teacher burnout and attrition rate in Ghana is high. The study seeks to identify the root causes of teacher burnout and how this phenomenon can be significantly minimized in Ghana. Data were collected from at least 10 active teachers, and a qualitative hermeneutic phenomenological approach was utilized to investigate the causes and effects of teacher burnout in Ghana. Semi structured in-depth interviews were conducted and the data analyzed to identify recurring themes. The findings revealed three fundamental causes of teacher burnout in Ghana; Poor working conditions, lack of remuneration and heavy workload. The study recommends the provision of teaching materials and other resources by the Ghana Education Service, as well as a comprehensive incentive packages for teachers to reduce teacher burnout in Ghana.
\end{abstract}

\section{INTRODUCTION}

It is an undisputable fact that teachers world-wide, contribute significantly towards the development of every nation. Hence, it is crucial that all the needs of teachers are met to ensure that they continue to train the citizenry for sustainable development. However, most teachers world-wide are stressed and are at risk of burnout as a result of poor working conditions (Armstrong, 2001). Locker (2007) observed that jobs are the central cause of burnout because most people spend most of their time at the workplace; teachers are no exception. Martinetz (2012) defined burnout as a feeling of stress and frustration that an individual can experience, which could culminate in attrition. According to Maslach and Jackson (1981), burnout is defined as "a syndrome of emotional exhaustion and cynicism that occurs frequently among individuals" (p. 99). Parker, Martin, Colmar and Liem (2012), outlined some of the signs of teacher burnout as illness, impatience, absenteeism, a lack of commitment, and poor job performance. Kyriancou (2001) intimated that teachers experiencing burnout have low commitment and enthusiasm towards their work which reflects in their job performance. Indeed, educators go through many obstacles that increase their burnout and stress levels. The educational system in Ghana has been undergoing a whole culture of changes and transformation and as a result, teachers are subjected to very stressful working conditions (Baah, 2009). However, stringent demands by teachers in Ghana had been treated with disdain, leading to industrial action in all public schools (Adanusa, 2014). Many teachers have found these changes stressful and have left the teaching profession due to burnout. Moreover, factors such as long hours at work, engaging in co-curricular activities, taking care of children and other domestic activities at home, increase the level of burnout among teachers.

\section{Statement of Problem}

\subsection{Burnout Amongst Teachers in Ghana}

Teacher burnout and stress is fast becoming a global phenomenon that needs to be addressed by all stakeholders in education. It is a problem with catastrophic consequences like the increase in the rate 

and Effects

of teacher attrition. A study by Jackson, Schwab, and Schuler (1986) in the United States amongst primary and secondary school teachers revealed that burnout is associated with a teacher's intention to leave the profession. The problem of teacher burnout is dominant, not only in developing nations like Ghana, but in advanced countries, such as the United States and Canada. In fact, Ghana's education sector continues to be plagued by many challenges since independence from British rule in 1957. Ghana, being one of the first countries in Sub-Saharan Africa to gain independence from British rule, has not seen much advancement in the economy, especially, the educational sector.

There has been an ever-heightening deep rooted partisan politics in Ghana, which has significantly crippled the fortunes and potential growth of Ghana's education sector as every government wants to implement its own educational policy. Each government that gets elected into office, wants to change the educational system to score political points. By so doing, hampering the gains choked by the previous administration in education.

\subsection{Purpose of the Study}

The purpose of this qualitative phenomenological study was to understand the meaning and essence of elementary schoolteachers' lived experiences of dealing with teacher burnout, which significantly causes increased teacher turnover in Ghana. The study again, sought to determine the extent to which living conditions have become factors that contribute to stress and burnout and motivate teachers to leave the profession.

\subsection{Significance of the Study}

The study examined the causes of teacher burn out among teachers at the elementary level within the Ghana Education Service (GES) in Ghana-West Africa. The current study may be used to provide useful information on how educational leaders can devise effective strategies to combat teacher burnout. From the African perspective, the study results may be used by education leaders to create strategies and organize professional development programs to ensure all needs of educators are met, thereby minimizing and/or eliminating teacher burnout.

Finally, leaders of other educational institutions could also make use of the findings by taking a radical stance in dealing with teacher burnout by providing incentives that could convince most educators to remain in the profession, thus reducing high teacher turnover. When implemented, the findings of the study could help policy makers to develop policies that could reverse the downward trend of teacher morale and status, so they can remain in the service. The results of the current study should unravel not only causes of teacher burnout, but the root causes of teacher burnout, and how to minimize its occurrence.

\subsection{Objectives of the Study}

The Objectives of the study are to:

- Find out why teachers leave the profession at the elementary schools in Ghana at a rampant rate due to stress and burnout.

- Determine the strategies educational leaders should adopt to curb to teacher burnout and stress and to reduce turnover rate among teachers in Ghana.

\section{Method}

A Qualitative phenomenological research design was utilized to undertake the study. Merriam (2009) mentioned that qualitative data involves information collected from the environment, including words from participants. Interviewing is the basic form of data collection in qualitative studies (Merriam, 2009). Silverman (2011) asserted that the use of interviews is an effective way of data collection, because it is used to encourage narrative responses that center on perceptions and experiences without invading the privacy of the participant.

Loftus and Higgs (2010) mentioned that qualitative research involves constructivism and constructionism; the former deals with construction of knowledge by individuals, while the latter expatiates on constructivism and the use of language (professional discourse) to shape the knowledge constructed (Schon, 1987). In support, Bakhtin (1986) intimated that knowledge construction is 
Teacher Burnout at the Elementary School Level in Ghana: A Qualitative Investigation into its Causes and Effects

contingent upon meaning attained via the relationships with the population of a study using face-toface dialogue.

\subsection{Population and Sampling}

Purposeful sampling technique was used to select 10 teachers, based on their experience in the teaching profession. Creswell (2014) defined purposeful sampling as the means by which a particular group of participants are chosen to participate in a study. Additionally, Patton (2002) mentioned that purposeful sampling strategies are a useful framework for thinking about who should be interviewed. Participants in the current study were contacted via principal of the school, who suggested participant names because they could provide the required information to enhance the success of the research. For confidentiality purposes, the participants were reported only as participants in the study. All participants were seasoned educators with masters and bachelor's degrees and were currently teaching in the elementary level.

Table 1 depicts the demographic data of the respondents. From that table, $60 \%$ of the participants are males, while $40 \%$ are females.

Table1: Gender Distribution of Respondents

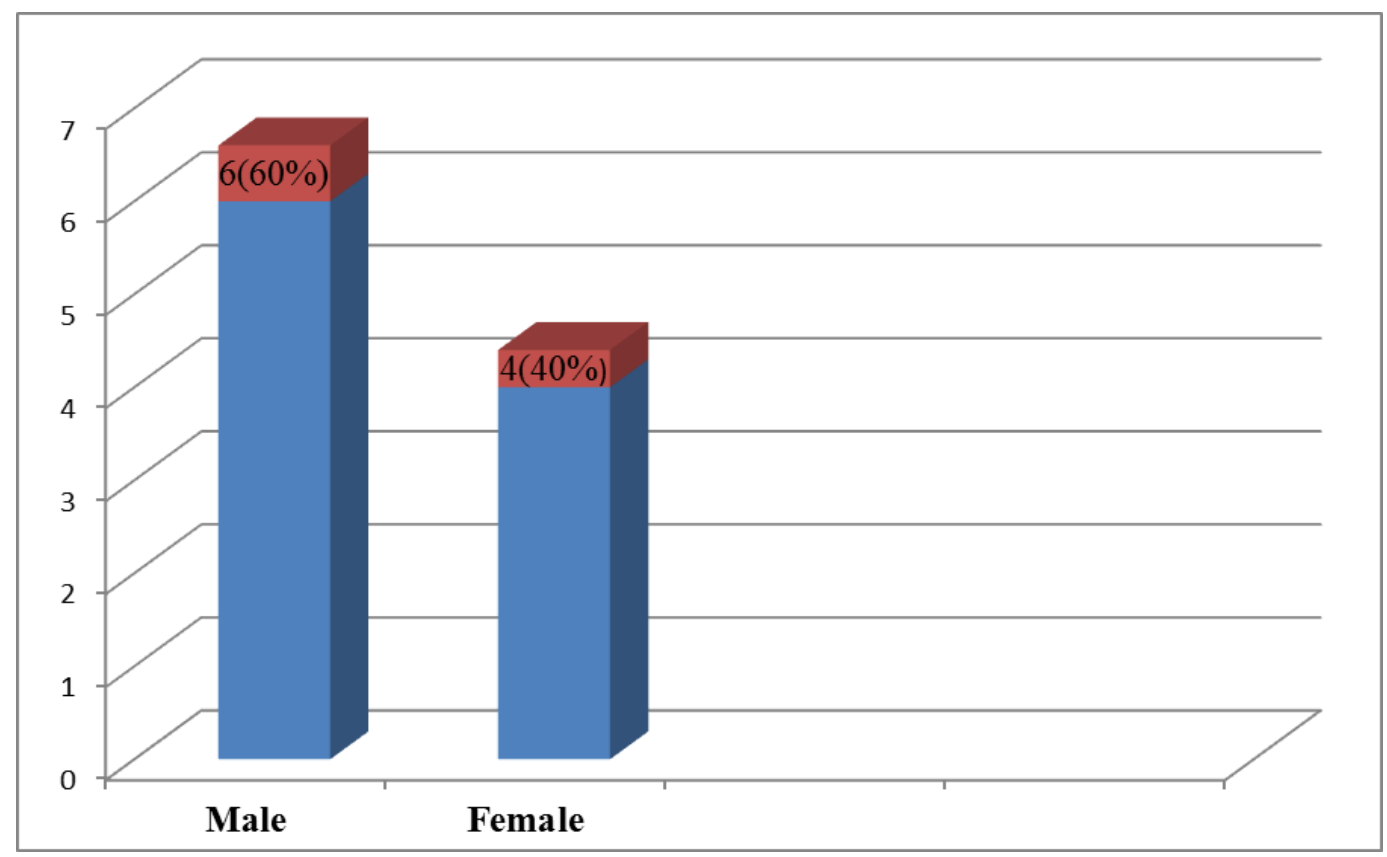

Source: Fieldwork, 2019.

Table 2 has details of the statistical data of participants. The oldest participant was $43 y e a r s$, and the youngest, 29. Two of them have master's degrees and the rest have degrees. Participants 2, 3, 4, and 10 served for 5, 7, 6 and 8years respectively, while participants 1, 5,6,7,8 and 9 served 3, 5, 2, 4, and 6years respectively in the elementary schools.

\begin{tabular}{|l|l|l|l|l|l|}
\hline No & Age of Respondent & Qualification & Rank in GES & Status & Service years \\
\hline 1 & 29 & BA & Teacher & At post & 3 \\
\hline 2 & & MA & Teacher & At Post & 5 \\
\hline 3 & 30 & BA & Teacher & At post & 7 \\
\hline 4 & 39 & BA & Teacher & At post & 6 \\
\hline 5 & 43 & MA & Teacher & At post & 5 \\
\hline 6 & 36 & M.Ed & Teacher & At post & 2 \\
\hline 7 & 28 & BA & Teacher & At post & 4 \\
\hline 8 & 32 & BA & Teacher & At Post & 6 \\
\hline 9 & 30 & BA & Teacher & At Post & 6 \\
\hline 10 & 35 & BA & Teacher & At Post & 8 \\
\hline
\end{tabular}

Note. $\mathrm{RSP}=$ Respondent;

Source: Fieldwork, 2019. 

and Effects

\subsection{Research Questions}

- How do teachers in Ghana perceive the factors they believe contribute to teacher burnout in light of their lived experiences?

- In what ways do teachers in Ghana explain the essence and meaningfulness of their lived experience of dealing with burn-out?

- How do teachers perceive their burnout impacting classroom instruction?

- How do teachers in Ghana describe teacher burnout?

\subsection{Procedures}

Frankel and Devers (2000) stated many factors are found to influence the type of instrumentation used in a qualitative research study. The first important factor is the purpose of the qualitative study. When a study is more exploratory, an open-ended protocol is appropriate (Paine, 2015). As a result, openended questions were adopted during the current study interviews. Simon (2006) indicated that the analysis of data requires creativity and circumspection based on the fact that the researcher analyzes raw data and organizes it into meaningful categories and interprets the data to make sense of it. The interviews in the current study were transcribed. Responses were first color coded according to the research questions and common themes carved out based on similarities.

\section{Data Analysis AND Results}

The Thematic analysis was adopted to analyze information collected. All the interview responses were recorded, and data from open-ended questions were collated and analyzed for recurring themes. According to Merriam (2009), coding is very important, because it is used to identify and summarize large amounts of data by grouping into categories; thereby, revealing themes. Transcripts were generated from the interviews and were coded to determine recurring themes. Some interview questions were administered via electronic format to obtain transcribed feelings and ideas concerning teacher burnout and deviant behavior (Simon, 2006). Creswell (2009) mentioned that the electronic form of data collection is used to allow the researcher to quickly obtain rich qualitative data from a large pool of participants.

Four research questions were created for the current study. Three themes emerged from the data: (a) poor conditions of service, (b) heavy workload, and (c) lack of reward/remuneration. All 10 participants mentioned the three fundamental themes. However, remuneration was the main theme that emerged from participant comments.

The first two themes emerged from responses to the first research sub question: How do teachers in Ghana perceive the factors they believe contribute to teacher burnout in light of their lived experiences? The answering themes included poor conditions of service.

Theme 1, Conditions of Service, was a part of all 10 participant comments, whether they lamented over the poor conditions of service or lack of job satisfaction in the Ghana Education Service. Participants maintained that teachers could leave their post if logistics were lacking in schools. Comments, such as lack of technology, maltreatment of teachers by school administrators, and meager salaries added to teachers' stress levels.

Theme 2, Heavy Workload, resulted in responses from 7 participants who noted problems, such as inadequate planning time and large class sizes. All participants alluded to the fact that they had to take work home, making it impossible to have a work-life balance.

Theme 3, Reward, emerged from the Research question 2: In what ways do teachers in Ghana explain the essence and meaningfulness of their lived experience dealing with burnout? The participants suggested remuneration and incentives to enable them to cope with the burnout and stress. To increase retention rates among teachers and reduce burnout in Ghana, incentives such as child education allowances, car maintenance allowances, and medical expense refunds were mentioned as conditions capable of minimizing teacher burnout and increasing the retention rate of teachers. 

and Effects

\section{RECOMMENDATION}

In order to proactively resolve the problem of teacher burnout and retain teachers within the Ghana Education Service, the government officials of Ghana, via the Ministry of Education, should consider the following recommendations:

- Public schools should focus on strategically reducing stress and burnout by implementing working arrangements that encourage a better relationship between employer and employees, which will discourage absenteeism and improve employee loyalty toward the organization. Public school officials should organize stress management training, and time and priority management training, workshop for their teachers to combat job stress and lead to high job satisfaction and performance while decreasing turnover.

- A satisfied teacher brings positive energy and desirable work ethics, leading to enhanced efficiency and positive behavioral outcomes. The analysis showed that level of job satisfaction was one of the factors that influence burnout, the government officials of Ghana need to face the challenge and find ways to increase job satisfaction to ensure that teachers are retained. Gatsinzi, Jesse, and Makewa (2013) supported the assertion by noting that teachers need to be supported and motivated to perform, and their motivation is influenced by factors such as school infrastructure, school policies, leadership, and good working conditions. The introduction of a bonus program, where teachers will be rewarded after a successful completion of a specified period of time, would be expedient.

- Experience, skills, and expertise in the profession should be part of the criteria for teacher recruitment, to help improve the efficacy level of teachers and give them the ability to overcome the challenging nature of the workload and teaching. The school leaders can also raise teacher self-efficacy using verbal persuasion, training, and development on issues regarding handling student discipline or workshops for professional training through external resources.

- Educational administrators should ensure that school settings improve teacher self-efficacy and job satisfaction by increasing instructional resources and updating all classrooms with modern technology. Teachers should be involved in key decision- making processes in the schools. It is also strongly recommended that a proactive and timely promotion scale formula for teachers be implemented to ensure teachers are compensated based on rank and years of service.

- Poor interpersonal relationships between some school leaders and teachers were also found to be a causal factor of teacher burnout in Ghana, especially concerning how some head teachers (leaders) and Ghana Education Service officers communicated with teachers. Poor relationships made teachers insecure in the service, and caused stress and burnout. School administrators should also provide mentoring to new teachers, offer teachers the opportunity to further their education, and ensure proper job-related supervision to bring the long-term result of better teacher outcomes, school success, and reduction of burnout.

A need exists for the Ghana Education Service officials to organize periodic professional development programs, in-service training, refresher courses, and on-the-job training to help upgrade teachers' pedagogical and social skills. The programs would be used to help give teachers the necessary support. The current study showed that job satisfaction is a major means of retaining teachers, hence upgrading the teacher skills would help ensure that teachers are satisfied with their job make them want to stay.

\section{CONCLuSion}

The current study regarding teacher burnout in Ghana showed three fundamental themes, all having a bearing on the research questions (a) poor conditions of service, (b) poor remuneration, and (c) heavy workloads. It was clear from the interviews that the conditions of service teachers in Ghana are appalling, especially the lack of teaching materials and modern technology to improve teaching and learning. The sad findings were found to stress the average Ghanaian teacher and discourage teachers from staying in the profession. One of the recommendations based on the current study is that school administrators have an invaluable role to ensure that teachers manage their stress and burnout and do not quit the profession. Principals and educational leaders should acknowledge the fact that working 

and Effects

collaboratively benefits all the stakeholders within their educational institutions, and this will foster effective communication and combat burnout. Burnout affects not only teachers. but students. One of the problems that the current study showed was that burnout causes unprecedented teacher absenteeism, which affects the instructor's abilities to provide effective instruction to students. Teacher burnout has become a global problem, and all stakeholders in education must develop concrete policies to combat the phenomenon. Teacher instability is found to affect student motivation and enthusiasm for learning; thus, it is important to identify and develop programs to help teachers learn to cope with burnout before it morphs into a larger problem, such as a high teacher attrition rates.

\section{RECOMMENDATIONS FOR FURTHER RESEARCH}

The problem of teacher burnout in Africa is real, and more teachers are leaving the teaching profession at an alarming rate. Since the current study was used to focus on a small sample of 10 teachers, it is recommended that a broader study be conducted in other regions of Ghana, encompassing both public and private schools. A study with a larger population would show a morevivid picture of teacher burnout. It is also highly recommended that a quantitative research approach be used to investigate the causes of teacher burnout in Ghana, with a specific region of Ghana selected for a study. Ghana has 10 administrative regions: (a) Greater-Accra, (b)Northern, (c) Central, (d) Western, (e) Ashanti, (f) Brong-Ahafo, (g) Upper East, (h)Upper West, (i) Eastern, and (j) Volta region. According to authors of a report published by modernghana.com, captioned "Ghana Now has 16 Regions Now" (2019), currently a constitutional instrument has been put before parliament for the creation of an additional six regions: (a) Oti, (b) Western North, (c) North East, (d) Ahafo, (e) Savannah, and (f)Bono East Regions.

\section{REFERENCES}

[1] Abdul-Rahman, N., Osei, A. F., Abdu, K. J., Arkorful, V., Basiru, I., \& Abdul, A. B. (2018). Teacher retention motivation strategies in Ghana. Education Quarterly Reviews, 1, 103-112. doi:10.31014/aior. 1993.01.01.11

[2] Adanusa, I. D. (2014, May 22). Press statement on unresolved grievances of teaching employees. GNAT News. Retrieved from http://www.openequalfree.org/ed- news/crisis-of- teacher-attrition-in-Ghana

[3] Akyeampong, K. (2002). Situational report on teacher demand, supply and retention. University of Cape Coast, Ghana.

[4] Armstrong, M. (2001). A handbook of human resource management practice (8th ed.). London, UK: Kogan Page.

[5] Baah, Y., Otoo, K. N., \& Osei-Boateng, C. (2009). Teacher attrition in Ghana: Results of a questionnaire survey. Ghana National Association of Teachers (GNAT) and Teachers and Educational Workers Union (TEWU), 1-42.

[6] Bakhtin, M. (1986). Speech genres and other late essays. Trans. V.W. McGee. Austin, TX: University of Texas Press.

[7] Creswell, J. W. (2009). Research design: Qualitative, quantitative, and mixed method approaches (3rd ed.). Thousand Oaks, CA: Sage.

[8] Creswell, John W. (2014). Research design: Qualitative, quantitative and mixed methods approaches (4th ed.). Thousand Oaks, CA: Sage.

[9] Danielson, C. (2007). Enhancing professional practice: A framework for teaching (2nd ed.). Alexandria, VA: Association for Supervision and Curriculum Development.

[10] Frankel, R. M. \& Devers, K. J. (2000). Study design in qualitative research-2, Sampling and data collection strategies. Education for Health, 13(2), 263-271.

[11] Gatsinzi, P., Jesse, R., \& Makewa, L. N. (2014). Work and school related variables in teacher motivation in Gasabo District, Rwanda. Journal of Education and Training, 1(2).

[12] Ghana Education Service, Teacher Education Division. (2004). Trends in education and school management in Ghana. Accra, Ghana: Author.

[13] Kyriacou, C. (2001). The nature and sources of stress facing teachers. Paper presented at the Third European Conference for Research on Learning and Instruction. Madrid, Spain.

[14] Locker, T. (2007). Managing stress. New Delhi: Sage.

[15] Loftus, S., \& Higgs, J. (2010). Researching the individual in workplace research, Journal of Education and Work, 23(4), 377-388. 

and Effects

[16] Martinetz, C. F. (2012). The stranglehold of state-mandated tests on education in the US: How to teach effectively in spite of this. Charleston, SC: Create Space Publishing.

[17] Merriam, Sharan B. (2009). Qualitative research: A guide to design and implementation (2nd ed.). San Francisco, CA: Jossey-Bass.

[18] Paine, G. (2015). A pattern-generating tool for use in semi-structured interviews. The Qualitative Report, 20(4), 468-481. Retrieved from https://search.proquest.com/docview/1682403686

[19] Parker, P. D., Martin, A. J., Colmar, S., \& Liem, G. A. (2012). Teachers' workplace well- being: Exploring a process model of goal orientation, coping behavior, engagement, and burnout. American Journal of Education, 28(4), 503-513. doi:10.1016/j.tate.2012.01.001

[20] Patton, M. Q. (2002). Qualitative research and evaluation methods (3rd ed.). Thousand Oaks, CA: Sage.

[21] Scheopner, A. J. (2010). Irreconcilable differences: Teacher attrition in public and Catholic schools. Educational Research Review, 5(3), 261-277. doi:10.1016/j.edurev.2010.03.001.

[22] Schön, D. A. (1987). Educating the reflective practitioner. San Francisco, CA: Jossey-Bass.

[23] Silverman, D. (2011). Doing qualitative research: A practical handbook (3rd ed.). Thousand Oaks, CA: Sage.

[24] Simon, M. (2006). Recipes for success: Dissertation \& scholarly research. Dubuque, IA: Kendall/Hunt

\section{AUTHOR'S BIOGRAPHY}

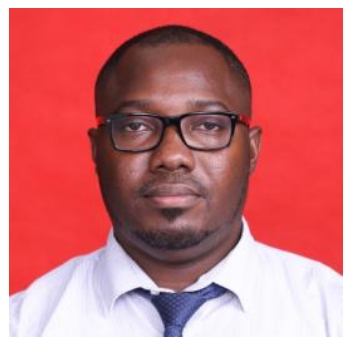

collection and synthesis), and proposal development skills.

Mr. Boateng is an educator, researcher, speaker, and human rights advocate who is passionately committed to student development and establishing productive learning environments. He possesses an in-depth knowledge of curriculum development and instructional design. Mr. Boateng also has a sound knowledge of K-12 and higher education academic policies and procedures, coupled with an excellent familiarity with current theories and practices in academic advising. He also has extensive research management experience, statistical, analytical, and data presentation skills (i.e. data

Citation: Solomon A. Boateng. "Teacher Burnout at the Elementary School Level in Ghana: A Qualitative Investigation into its Causes and Effects". International Journal of Humanities Social Sciences and Education (IJHSSE), vol. 7, no.1, 2020, pp. 17-23. doi: http://dx. doi.org/10.20431/2349-0381.0701002.

Copyright: () 2020 Authors. This is an open-access article distributed under the terms of the Creative Commons Attribution License, which permits unrestricted use, distribution, and reproduction in any medium, provided the original author and source are credited. 